\title{
Survei Kemampuan Teknik Dasar Passing Bawah Ekstrakurikuler Bolavoli
}

\author{
Bagus Prayogatama ${ }^{1 \star}$ \\ 'Jurusan Pendidikan Jasmani, Kesehatan dan Rekreasi, Fakultas Ilmu Keolahragaan, \\ Universitas Negeri Malang, Jalan Semarang No 5, Malang, Jawa Timur, 65145, Indonesia \\ *Penulis koresponden: prayogatama4@gmail.com, 085655552990
}

Artikel diterima: 12 Maret 2020; direvisi: 23 Januari 2021; disetujui: 26 Januari 2021

\begin{abstract}
This studyaims to determine the basic technical skills of passing under byusing tests on extracurricular participants at SMP Negeri 5 Jombang. This study uses descriptive quantitative data analys is with survey research methods. The research subjects were volleyball extracurricular members at SMP Negeri 5 Jombang whichconsisted of 18 students. Based on the results of the study, the results of the data analysis on the basic skills of passing under volleyball for the male extracurricular participants were in the moderate category and for the process assessment was included in the sufficient category, while the female volleyball extracurricular participants were in the sufficient category for the outcome assessment and process assessment. So there is $25 \%$ good, $25 \%$ good enough and $50 \%$ good enough.
\end{abstract}

Keyword: volleyball, under-passing, extracurricular activities

Abstrak: Penelitian ini menggunakan analisis data deskriptif kuantitatif dengan metode penelitian survey. Subjek penelitian adalah peserta ekstrakurikuler bolavoli SMP Negeri 5 Jombang yang terdiri dari 18 siswa. Berdasarkan hasil penelitian bahwa hasil analisis data tes keterampilan dasar passing bawah bolavoli peserta ekstrakurikuler putra masuk dalam kategori sedang dan untuk penilaian proses termasuk dalam kategori cukup sedangkanpeserta ekstrakurikuler bolavoli putri termasuk dalam kategori cukup untuk penilaian hasil dan penilaian proses. Jadi ada $25 \%$ baik, $25 \%$ cukup dan $50 \%$ cukup.

Kata kunci: bolavoli, passing bawah, ekstrakurikuler

\section{PENDAHULUAN}

Kegiatan ekstrakurikuler kegiatan yang dilaksanakan ketika jam pelajaran sekolah selesai yang mempunyai tujuan untuk memfasilitasi minat dan bakat siswa. Kegiatan ekstrakurikuler selain untuk memfasilitasi peserta didik, juga mempunyai tujuan untuk mengembangkan agar peserta didik dapat berprestasi di bidang non akademik, diantaranya yaitu bolavoli.

Menurut Yudiana (2015:96) "permainan olahraga bolavoli merupakan aktivitas fisik yang ada dalam kelompok aktivitas permainan dan sport". Sejalan dengan pernyataan tersebut,"bolavoli yaitu olahraga bolabesar dan termasuk beregu karena dimainkan oleh dua tim" (Amin, 2017:2). Penelitian Heri dkk (2016:1) permainan bolavoli yaitu memvolley bola di udara hilir mudik dengan maksud mencari kemengan dari lawan.

Menurut Nešić, dkk (2013), bolavoli adalah olahraga yang atraktif, menarik, kompleks dan dinamis dimana untuk setiap regu ingin mendapatkan suatu kemenangan. Selaras dengan pendapat tersebut Sharma (2017) 
mengatakan bahwa, permainan bolavoli merupakan permainan yang terdapat defensive dan offensive, dalam permainan ini terdapat teknik dasar yang harus dikuasai seperti smash, service, umpan dan passing. Pemain bolavoli idealnya harus mempunyai kondisi fisik dan mental yang bagus agar menjadi atlet yang unggul (Hidayat, dkk., 2019) (Vieira et al., 2017).

Bolavoli adalah kegiatan ekstrakurikuler yang dilakukan di SMP Negeri 5 Jombang dengan jumlah peserta sebanyak 27 orang. Kegiatan ekstrakurikuler bolavoli dilaksanakan di lapangan bolavoli SMP Negeri 5 Jombang pada hari Selasa pukul 16.00-17.00 WIB.

Untuk dapat mencapai tujuan bermain bolavoli yaitu meraih kemenangan dengan menciptakan permainan yang baik, maka pemain diharuskan menguasai teknik dasar bolavoli yang baik juga. Menurut Primiatiningsih (2015:15), teknik dasar bolavoli ada empat yaitu : service, passing, smash dan block. Selaras dengan pendapat tersebut, Permainan olahraga bolavoli terdapat beberapa teknik dasar yaitu service, passing, umpan dan blok (Sukri, 2019:2)

Roesdiyanto (2014:105), mengatakan bahwa passing adalah teknik dasar bolavoli yang berperan penting untuk membangun serangan kepada lawan dan meraih kemenangan. Menurut penelitian (Nurcahyono \& Priambodo, 2013), passing adalah usaha pemain untuk menyajikan bola terhadap teman seregunya agar dapat melakukan smash terhadap regu lawan. Upaya seorang atlit suatu teknik tertentu untuk memberikan bola kepada teman setimnya dan dimainkan sendiri adalah passing (Kusworo, 2018).

Menurut Supriadi (2018:14), teknik dasar passing bawah merupakan kegiatan yang untuk menerima serangan smash dari tim lawan dan menggunakan lengan tangan bagian bawah. Sejalan dengan pernyataan tersebut passing bawah adalah teknik yang dominan digunakan untuk menciptakan serangan dan menghasilkan point (Fitriansyah, 2019). Suparjo (2014:15) Berpendapat bahwa, passing bawah digunakan untuk mencari bola rendah yang datang dan mengambol bola yang terpental jauh dari lapangan pertandingan.

Berdasarkan pengamatan tim bolavoli SMP Negeri 5 Jombang pada saat melakukan latihan peneliti dapat menemukan kelemahan peserta ekstrkurikuler bolavoli SMP Negeri 5 Jombang yaitu seringkali melakukan kesalahan pada teknik dasar passing bawah, bahwa arah pantulan bola peserta ekstrakurikuler banyak yang masih tidak terarah dan tidak teratur. Setelah dilakukan wawancara peneliti dengan pelatih ekstrakurikuler bolavoli di SMP Negeri 5 Jombang terkait mengapa tim bolavoli SMP Negeri 5 Jombang prestasinya menurun bahkan tidak dapat menembus babak semifinal dalam berbagai kompetisi antar pelajar di Kabupaten Jombang, ternyata program latihan yang dilakukan hanya fokus pada materi latihan game. Materi latihan passing bawah, kurang difokuskan karena pembina dan pihak dari sekolah hanya menyediakan waktu dan tempat sekali dalam seminggu dan hanya 1 jam. Maka, pada saat bertanding sering tidak terkontrol dengan baik dan permainan tidak berjalan dengan maksimal.

Berdasarkan hasil wawancara kepada pelatih ektrakurikuler bolavoli di SMPN 5 Jombang, bahwa waktu latihan yang terbatas akan berpengaruh tidak baik pada kemampuan para peserta ekstrakurikuler yaitu hanya dilaksanakan satu kali disetiap minggunya. Pelatih juga mengatakan bahwa terdapat salah satu teknik dasar bolavoli yang kurang dikuasai oleh peserta ekstrakurikuler yaitu passing bawah.

Didukung dengan observasi yang dilakukan peneliti di SMPN 5 Jombang, peneliti memperoleh hasil sebagai berikut: beberapa peserta ekstrakurikuler bolavoli kurang memperhatikan pelatih saat melakukan latihan baik dalam metode drill teknik dasar passing bawah bolavoli dan permainan, sehingga peserta ekstrakurikuler bolavoli tidak maksimal saat melakukan passing bawah yang pada akhirnya peserta tidak mendapatkan hasil yang baik.

Sebelum peneliti memberi kesimpulan dari penelitian mengenai passing peserta ekstrakurikuler bolavoli SMP Negeri 5 Jombang, maka peneliti memaparkan penelitian yang terdahulu. Berdasarkan penelitian yang dilakukan oleh Widiayantoro (2015), diketahui bahwa tes keterampilan teknik dasar passing bawah peserta ekstrakurikuler bolavoli di SMP Negeri 4 Gombong mengikuti untuk mengetahui kemampuan passing bawah siswa yang tergolong kurang sekali sejumlah 7 siswa dan persentase $23,3 \%$, kurang 13 peserta 43,4\%, sedang 7 peserta $23,3 \%$, baik 0 siswa $0 \%$, baikk sekali 3 peserta $10 \%$.penelitian yang dilakukan oleh Widiyantoro dapat disimpulkan bahwa keterampilan teknik dasar passing bawah bolavoli SMP Negeri 4 Gombong termasuk dalam kategori kurang. Penelitian (Koloay, 2017) yaitu, siswa kelas XI MIPA SMAN 2 Singaraja dapat berkembang dengan metode tipe koperatif dapat meningkatkan kemampuan pasing. 


\section{METODE}

Berdasarkan tujuan dari penelitian ini, yaitu mengetahui kemampuan keterampilan teknik dasar passing bawah peserta ekstrakurikuler bolavoli SMP Negeri 5 Jombang dengan menggunakan tes passing bawah dari Clifton, maka peneliti menggunakan metode survei. Subjek dalam penelitian ini peserta ekstrakurikuler bolavoli SMP Negeri 5 Jombang dengan jumlah peserta 27 orang. Sumber data dalam penelitian ini adalah pelatih ekstrakurikuler bolavoli SMP Negeri 5 Jombang dan peserta ekstrakurikuler bolavoli SMP Negeri 5 Jombang sebanyak 27 orang dengan menggunakan lembar penilaian dan catatan lapangan.

Sesuai dengan tujuan penelitian ini, maka analisis data yang digunakan dalam penelitian ini adalah dengan mengolah data dalam bentuk angka dan perhitungan menggunakan statistik dan akan dideskripsikan dalam bentuk narasi.

HASIL

Berdasarkan hasil penelitian, tes kemampuan keterampilan teknik dasar passing bawah bolavoli yang telah dilakukan pada peserta ekstrakurikuler bolavoli di SMPN 5 Jombang terdapat 27 peserta ekstrakurikuler bolavoli terdiri dari 20 putra dan 7 putri yang berusia 13-15 tahun yang dianalisis dengan deskriptif, kuantitatif. Hasil yang diperoleh sebagai berikut:

Tabel 1 Klasifikasi Hasil Tes Keterampilan Teknik Dasar Passing Bawah Bolavoli Putra

\begin{tabular}{cccc}
\hline Jumlah Nilai & Golongan & $F$ & $\%$ \\
\hline 21 ke atas & Baik & 5 & $25 \%$ \\
$13-20$ & Cukup & 5 & $25 \%$ \\
$3-12$ & Sedang & 10 & $50 \%$ \\
2 kebawah & Kurang & 0 & $0 \%$
\end{tabular}

Pada Tabel 1, dapat diketahui bahwa hasil analisis persentase tes keterampilan teknik dasar passing bawah bolavoli pada peserta ekstrakurikuler putra di SMPN 5 Jombang untuk kategori baik terdapat 5 peserta pada persentase $25 \%$, kategori cukup 5 peserta dengan persentase $25 \%$, kategori sedang sebanyak 10 peserta pada persentase $50 \%$.

Tabel 2 Klasifikasi Hasil Tes Keterampilan Teknik Dasar Passing Bawah Bolavoli Putri

\begin{tabular}{cccc}
\hline Jumlah Nilai & Golongan & $\mathrm{F}$ & $\%$ \\
\hline 21 ke atas & Baik & 0 & $0 \%$ \\
$13-20$ & Cukup & 6 & $85 \%$ \\
$3-12$ & Sedang & 1 & $14 \%$ \\
2 kebawah & Kurang & 0 & $0 \%$ \\
& & & \\
\hline
\end{tabular}

Pada Tabel 2, dapat diketahui bahwa hasil analisis persentase tes keterampilan teknik dasar passing bawah bolavoli pada peserta ekstrakurikuler putri di SMPN 5 Jombang untuk kategori cukup 6 peserta dengan persentase $85 \%$, kategori sedang 1 peserta dengan persentase $14 \%$.Berdasarkan hasil penilaian proses tes kemampuan keterampilan teknik dasar passing bawah bolavoli yang telah dilakukan pada peserta ekstrakurikuler bolavoli di SMPN 5 Jombang terdapat 27 peserta ekstrakurikuler bolavoli terdiri dari 20 putra dan 7 putri yang berusia 13-15 tahun adalah sebagai berikut:

Tabel 3 Data Hasil Tes Penilaian Proses Keterampilan Teknik Dasar Passing Bawah Bolavoli Putra

\begin{tabular}{ccccc}
\hline No. & F & Jumlah & Nilai & Kategori \\
\hline 1 & 5 & 73 & 92.25 & Sangat \\
2 & 5 & 52 & 65 & Baik \\
3 & 10 & 74 & 46.25 & Baik \\
& & & & Cukup \\
\hline
\end{tabular}


Pada Tabel 3, dapat diketahui bahwa hasil penilaian proses tes keterampilan teknik dasar passing bawah bolavoli pada peserta ekstrakurikuler putra di SMPN 5 Jombang untuk kategori sangat baik sebanyak 5 peserta dengan nilai 92.25 , kategori baik sebanyak 5 peserta dengan nilai 65 dan kategori cukup sebanyak 10 peserta dengan nilai 46.25 .

Tabel 4 Data Hasil Tes Penilaian Proses Keterampilan Teknik Dasar Passing Bawah Bolavoli Putri

\begin{tabular}{ccccc}
\hline No. & F & Jumlah & Nilai & Kategori \\
\hline 1 & 4 & 31 & 46.9 & Cukup \\
2 & 3 & 16 & 33.3 & Kurang \\
\hline
\end{tabular}

Pada Tabel 4, diketahui bahwa hasil penilaian proses tes keterampilan teknik dasar passing bawah bolavoli pada peserta ekstrakurikuler putri di SMPN 5 Jombang untuk kategori cukup ada 4 peserta dengan nilai 46.9, kategori kurang ada 3 peserta dengan nilai 33.3.

Berdasarkan hasil penelitian yang sudah dipaparkan pada Table 1 sampai 4, dapat disimpulkan bahwa hasil analisis data tes keterampilan dasar passing bawah bolavoli peserta ekstrakurikuler bolavoli putra termasuk di kategori sedang dan untuk penilaian proses termasuk dalam kategori cukup sedangkan peserta ekstrakurikuler bolavoli putri termasuk dalam kategori cukup untuk penilaian hasil dan penilaian proses.

\section{PEMBAHASAN}

Penelitian ini, penelitian survey yang bertujuan mengetahui teknik dasar passing bawah bolavoli pada peserta ekstrakurikuler bolavoli di SMPN 5 Jombang. Penelitian ini menggunakan tes Clifton. Teknik pengambilan data pada penelitian ini menggunakan tes. Subjek dari penelitian ini sebanyak 27 peserta didik yang mengikuti ekstrakurikuler bolavoli SMPN 5 Jombang.

Dari hasil pengumpulan data penelitian tes keterampilan dasar passing bawah dapat disimpulkan bahwa peserta ekstrakurikuler bolavoli SMPN 5 Jombang yang berusia 13-15 tahun secara keseluruhan 27 yang terdiri dari 20 putra dan 7 putri, terdapat 5 peserta putra yang tergolong dalam kategori sangat baik, terdapat 5 peserta putra dan 6 peserta putri yang tergolong dalam kategori cukup, terdapat 10 peserta putra dan 1 peserta putri yang tergolong dalam kategori sedang.

Selaras dengan hasil penelitian yang dilakukan oleh Tammam (2017:66) di SMPN 1 Maron, bahwa hasil tes kemampuan keterampilan teknik dasar passing bawah putra dan putri untuk usia 13-15 tahun tergolong dalam cukup. Pada data diatas bisa disimpulkan bahwa kemampuan keterampilan teknik dasar passing bawah bolavoli pada anak SMP usia 13-15 tahun rata-rata tergolong dalam kategori cukup.

Berdasarkan hasil penelitian yang dilakukan oleh peneliti, perbedaan kategori disetiap peserta dapat dipengaruhi oleh beberapa faktor, mulai dari sikap persiapan, yaitu : posisi kaki yang terlalu tegak dan posisi tangan yang cenderung kaku, sikap perkenaan bola, yaitu bola tidak pas mengenai sisi tangan bagian bawah dan pantulan bola yang kurang stabil, dan sikap akhir, yaitu : tidak mengikuti arah bola yang datang dan tidak mengambil posisi siap kembali ketika bola datang. Kesalahan terjadi ketika melakukan passing adalah 1) kedua lengan tidak sejajar (salah satu lengan terlalu tinggi dalam bersikap), 2) kuda-kuda kaki kurang merendah, 3) ayunan tangan terlalu keras sehingga bola tidak dapat dikuasai dengan baik, 4) lengan terpisah sebelum menerima bola.

Untuk memperbaiki passing bawah bolavoli dapat dilakukan dengan cara: 1) biarkan bola bergerak sampai sepinggang sebelum mampassing, 2) tekuk lutut dan tetap bertahan pada posisi tubuh rendah, 3) badan bertumpu di kaki depan dan badan condong ke depan, 4) tetap pada posisi siap, 5) lengan posisi sejajar paha dan terima bola jauh (Viera, 2004:21). Apabila peserta ekstrakurikuler melakukan gerakan perbaikan tanpa ada kesalahan maka dengan otomatis bola akan terarahkan dan mudah dijangkau. Akan tetapi untuk meningkatkan teknik dasar passing bawah bolavoli diperlukan suatu latihan yang berulang-ulang untuk mendapatkan kemampuan yang maksimal. 


\section{KESIMPULAN}

Berdasarkan penelitian tentang survei keterampilan dasar passing bawah bolavoli peserta ekstrakurikuler di SMPN 5 Jombang yang berusia 13-15 tahun dapat disimpulkan bahwa terdapat 5 peserta putra dari 20 peserta dengan persentase $25 \%$ termasuk dalam kategori baik, sebanyak 5 peserta dari 20 peserta dengan persentase $25 \%$ termasuk dalam kategori cukup, sebanyak 10 peserta dari 20 peserta dengan persentase $50 \%$ termasuk dalam kategori sedang dan untuk peserta putri 6 peserta dari 7 peserta dengan pesentase $85 \%$ termasuk dalam kategori cukup serta 1 peserta putri dari 7 peserta dengan pesentase 14\% termasuk dalam kategori sedang. Jadi rata-rata kemampuan keterampilan teknik dasar passing bawah bolavoli peserta putra ekstrakurikuler di SMPN 5 Jombang tergolong dalam kategori sedang dan untuk rata-rata kemampuan keterampilan teknik dasar passing bawah bolavoli peserta putri ekstrakurikuler di SMPN 5 Jombang tergolong dalam kategori cukup.

\section{DAFTAR PUSTAKA}

Amin, A. (2016). Hasil Belajar Passing Bawah Bola Voli Gaya Mengajar Komando dan Gaya mengajar Resiprokal Siswa Kelas IX Di SMP Negeri 9 Yogyakarta. Pendidikan Jasmani, 1-10.

Fitriansyah, T. (2019). Pengaruh Latihan Passing Bawah Dengan Alat Terhadap Kemampuan Teknik Passing Bawah Klub Bola Voli Yuso Gunadarma Yogyakarta. Pendidikan Jasmani, 4, 5-10.

Heri, J., Supriatna, E., \& Purnomo, E. (2013). Survey Ketrampilan Teknik Dasar Bola Voli Pada Siswa Putra Yang Mengikuti Ekstrakurikuler Di SMA Negeri 4 Pontianak. Journal of Chemical Information and Modeling, 53(9), 1689-1699. https://doi.org/10.1017/CBO9781107415324.004

Hidayat, A., Pratama, R., \& Khudri, A. (2019). Development of test devices and measurement of passing computer based volleyballs. Journal of Physical Education, 6(1), 158-162.

Koloay, C. C. J. (2017). Implementasi Model Kooperatif Tps Meningkatkan Aktivitas Hasil Belajar Passing Bola Voli. Jurnal Penelitian Dan Pengembangan Pendidikan, 1(3), 98-109. https://doi.org/10.23887/jppp.v1i3.12629

Kusworo, D. (2018). Artikel Survei Servis Bawah Dan Passing Bawah Bolavoli Pada Siswa Putra Kelas VII SMP / MTSN Se Kecamatan Plandaan Kabupaten Jombang Tahun Pelajaran 2017 / 2018. Oleh : DWI KUSWORO Dibimbingoleh: Program StudiPenjaskesrek Fakultas Keguruan Dan IImu Pend. 02(04), 110.

Nešić, G., llić, D., Majstorović, N., Grbić, V., \& Osmankač, N. (2013). Training Effects on General and Specific Motor Skills on Female Volleyball Players 13-14 Years Old. Sportlogia, 9(2), 119-127. https://doi.org/10.5550/sgia.130902.en.007n

Nurcahyono, F. H., \& Priambodo, A. (2013). Hubungan Antara Konsentrasi Siswa dengan Ketepatan Passing Bawah dalam Permainan Bolavoli ( Studi Pada Siswa Kelas X Jurusan Administrasi Perkantoran SMK Negeri 1 Boyolangu Tulungagung Tahun Ajaran 2012 / 2013 ) Febri Hari Nurcahyono Anung Priambodo Abstr. Jurnal Pendidikan Jasmani UNESA Surabaya, 02(01), 2013-2015.

Sharma, R. (2017). Efficacy of imagery training in improving the skill performance of volleyball players. 2(2), 705-707.

Sukri. (2019). Survei Kemampuan Servis Bawah Dan Passing Bawah Bola Voli SMP Negeri 1 Makassar. Pendidikan Jasmani, 1-8.

Suparjo, J. (2014). Meningkatkan keterampilan gerakan passing bawah pada permainan bola voli melalui metode tutorial teman sebaya siswa kelas viii a smp negeri 4 putri hijau. Universitas Bengkulu.

Supriadi. (2018). Survei Kemampuan Passing Bawah Bola Voli Siswa Kelas VII SMP Negeri 26 Makassar. Universitas Negeri Makasar.

Vieira, L. H. P., De Andrade, V. L., Aquino, R. L., Moraes, R., Barbieri, F. A., Cunha, S. A., ... Santiago, P. R. (2017). Construct validity of tests that measure kick performance for young soccer players based on cluster analysis: Exploring the relationship between coaches rating and actual measures. Journal of 
Sports Medicine and Physical Fitness. https://doi.org/10.23736/S0022-4707.16.06863-8

Widiayantoro, P. (2015). Tingkat kemampuan. Universitas Negeri Yogyakarta.

Yudiana, Y. (2015). Implementasi Model Pendekatan Taktik dan Teknik dalam Pembelajaran Permainan Bola Voli pada Pendidikan Jasmani Siswa Sekolah Menengah Pertama. Kajian Pendidikan, 5(1), 95-114. 